\title{
Asymmetric Defaultable Interest Rate Swap Valuation and Bilateral Credit Value Adjustment
}

\author{
Alan White ${ }^{1}$ \\ FinPricing \\ http://www.finpricing.com
}

\begin{abstract}
The unilateral defaultable claim valuation problems have been studied extensively, but the valuation of a bilateral contingent claim with asymmetric credit qualities is still lacking convincing mechanism. This paper presents an analytical model for valuing contingent claims, e.g., interest rate swaps, subject to default by both counterparties. The default-free interest rates are modeled by the Market Models, while the default time is modeled by the reduced-form model as the first jump of a time-inhomogeneous Poisson process. All quantities modeled are market-observable. The closed-form solution gives us a better understanding of the impact of the credit asymmetry on swap value, credit value adjustment, swap rate and swap spread.
\end{abstract}

Key words: defaultable interest rate swap, bilateral defaultable claim, credit asymmetry, market models, Black model, LIBOR market model, reduced-form model, credit value adjustment, swap spread.

\footnotetext{
${ }^{1}$ Email: alan.white@ finpricing.com; Url: http://www.finpricing.com
} 


\section{Introduction}

Interest rate swap (IRS) is one of the most popular financial derivatives. In the market, IRS's are quoted irrespective of credit ratings of counterparties. In another words, they are considered as default-free. The valuation of default-free IRS's under a term structure of interest rates is a classical exercise. However, swap contracts are traded over-the-counter (OTC) and are not backed by the guarantee of a clearing corporation or an exchange. As a consequence, each party is exposed to the credit risk (default risk). Historical experience shows that credit risk often leads to significant losses. Therefore, one should incorporate the cost of the counterparty risk into the swap price. Also, regulatory issues related to the Basel II framework encourage the inclusion of default risk into valuation.

Pricing defaultable derivatives or pricing the counterparty credit risk is a relatively new area of derivatives modeling and trading. Credit value adjustment (CVA) allows us to quantify counterparty credit risk as a single, measurable Profit \& Loss number. By definition, CVA is the difference between the risk-free trade value and the true (or risky or defaultable) trade value that takes into account the possibility of counterparty's default. Commonly, the CVA is not paid as a lump-sum upfront premium, but rather is structured into a funding spread. The risk-free trade value is what brokers quote or what trading systems or models normally report. The defaultable trade value, however, is a relatively less explored and less transparent area, which is the main challenge and core theme for credit risk adjustment.

IRS is a typical bilateral contingent contract that can be either an asset or a liability to each party during the life of the contract. Unlike the unilateral defaultable claim valuation problems that have been studied extensively by many authors, the valuation of bilateral contingent claims is still lacking convincing mechanism. The 
problem is mainly caused by the asymmetric credit qualities and the asymmetric default settlement rules.

Sundaresan (1991), Longstaff and Schwartz (1993), and Tang and Li (2007) simplify the problem by considering the IRS as a simple exchange of loans (receivable parts and payable parts). It is inappropriate to value a defaultable IRS by pricing the default risk of the promised gross payment from each party separately and then adding the two together. Because the promised cash flow exchange in an IRS is always netted. Another simplification consists of taking into account the presence of one risky counterparty only, as in Li (1998) and Arvanities and Gregory (2001). These approaches overlook the presence of bilateral default risk.

The first study on asymmetric defaultable IRS is conducted by Duffie and Huang (1996). They use a short rate interest rate model combined with a reducedform default model and lead to numerical approximations by solving a recursive integral. Even the authors admit that it is a substantial complexity solution. Hubner (2001) extends the work carried out by Duffie and Huang (1996) and gets a closedform solution by introducing a one-dimensional state variable $X$ that can be thought of as a ratio of the market value of the firm's assets. The author, however, does not show how to calibrate the state variable and not even provide a simple example. In general, these proposed models are not practical enough to use.

In this paper, we present an analytical model for valuing contingent claims subject to default by both parties. While the general principles of the valuation model can be applied to other bilateral defaultable contingent claims, we focus on the valuation of defaultable IRS's in which both parties are exposed to credit risk. The approach is based on market models for interest rates and a reduced-form model for the default time. All quantities modeled are market-observable. With the closed-form solution, we can analyze the impact of credit risk on swap value, swap rate, swap 
spread and CVA more closely. We confirm the results in Duffie and Huang (1996) and also report some new findings.

The rest of this paper is organized as follows: Market models are discussed in Section 2. In section 3, the valuation of asymmetric defaultable IRS and CVA are elaborated. The results are presented in Section 4. The conclusions are given in Section 5.

\section{Market Models}

Consider an increasing maturity structure $0 \leq T_{0}<T_{1}<\ldots<T_{N}$ from which expiry-maturity pairs of dates $\left(T_{k-1}, T_{k}\right)$ for a family of spanning forward rates are taken. The simply compounded forward rate reset at $\mathrm{t}$ for forward period $\left(T_{k-1}, T_{k}\right)$ is defined by

$$
F_{k}(t):=F\left(t ; T_{k-1}, T_{k}\right)=\frac{1}{\tau_{k}}\left(\frac{P\left(t, T_{k-1}\right)}{P\left(t, T_{k}\right)}-1\right)
$$

where $P(t, T)$ denotes the time t price of a zero-coupon bond maturing at time $\mathrm{T}$ and $\tau_{k}:=\tau\left(T_{k-1}, T_{k}\right)$ is the accrual factor or day count fraction for period $\left(T_{k-1}, T_{k}\right)$.

Consider a zero coupon bond numeraire $P\left(\cdot, T_{i}\right)$ whose maturity coincides with the maturity of the forward rate $F_{i}$. The measure $Q^{i}$ associated with $P\left(\cdot, T_{i}\right)$ is called $T_{i}$ forward measure.

The name 'market model' refers to the modeling of market observable variables such as forward rates and swap rates. The explicit modeling market rates allows for natural formulas for interest rate option volatility, that are consistent with the market practice of using the formula of Black for caps and swaptions. The typical 
market models are Black model, LIBOR market model (LMM) and swap market model (SMM).

The Black model is a variant of the Black-Scholes option pricing model and consists of a series of forward measures. Each forward rate is modeled by a lognormal process under its own forward measure. The forward rate dynamics under the Black model is

$$
d F_{k}(t)=\sigma_{k} F_{k}(t) d W_{k}(t)
$$

where $\sigma_{k}$ is the Black caplet volatility or the spot volatility of the forward rate $F_{k}$; $W_{k}(t)$ is a Brownian motion

The solution to equation (2) can be expressed as

$$
\begin{aligned}
F_{k}(T) & =F_{k}(t) \exp \left(-\frac{\sigma_{k}^{2}}{2}(T-t)+\sigma_{k}\left(W_{k}(T)-W_{k}(t)\right)\right) \\
& =F_{k}(t) \exp \left(-\frac{\sigma_{k}^{2}}{2}(T-t)+\sigma_{k} W_{k}(T-t)\right)
\end{aligned}
$$

The LMM, in contrast to the Black model, describes the dynamic of a whole family of forward rates under a common measure.

Under the lognormal assumption and the forward measure $Q^{i}$, the forward rate $F_{k}(t)$ of LMM follows the following dynamics:

$$
\begin{aligned}
& \text { Case 1. } \quad \mathrm{i}<\mathrm{k}, t \leq T_{i}: \quad d F_{k}(t)=v_{k}(t) F_{k}(t) \sum_{j=i+1}^{k} \frac{\rho_{k j} \tau_{j} v_{j}(t) F_{j}(t)}{1+\tau_{j} F_{j}(t)} d t \\
& +v_{k}(t) F_{k}(t) d W_{k}(t) \\
& \text { Case 2. } \quad \mathrm{i}=\mathrm{k}, t \leq T_{k-1} \quad d F_{k}(t)=v_{k}(t) F_{k}(t) d W_{k}(t) \\
& \text { Case } 3 . \quad \mathrm{i}>\mathrm{k}, t \leq T_{k-1} \\
& d F_{k}(t)=-v_{k}(t) F_{k}(t) \sum_{j=k+1}^{i} \frac{\rho_{k j} \tau_{j} v_{j}(t) F_{j}(t)}{1+\tau_{j} F_{j}(t)} d t \\
& +v_{k}(t) F_{k}(t) d W_{k}(t)
\end{aligned}
$$


where $v_{k}(t)$ is the instantaneous volatility. We further assume that the Brownian motions $W_{k}(t)$ and $W_{j}(t)$ of different forward rates $F_{k}(t)$ and $F_{j}(t)$ are instantaneously correlated according to $\rho_{k j}$, i.e.,

$$
d W_{k}(t) d W_{j}(t)=\rho_{k j} d t
$$

For a vanilla instrument like swap or cap, the payoff can be decomposed additively into a sum of sub-payoffs (each is involved with a single forward rate and associated with a contract called swaplet or caplet). We can evaluate each sub-

payoff separately and sum corresponding results together. For each sub-payoff, the joint dynamics of forward rates is not involved. As a consequence, the correlation between different rates does not afflict the sub-payoff, since marginal distribution of the single forward rate is enough to compute the expectation appearing in the subpayoff. In other words, the correlations between different forward rates are not relevant to these kinds of vanilla products. As matter of fact, the valuations for these vanilla products under either the LMM or the Black model should be equivalent; otherwise it will violate the fundamental single value rule and create an arbitrage opportunity (see Proposition 6.4.1 of Brigo-Mercurio (2006)).

\section{Swap Valuation and CVA}

We consider a filtered probability $\operatorname{space}(\Omega, \mathcal{F}, \mathcal{P})$ with a filtration $\mathcal{F}_{t}$ satisfying the usual conditions, where $\Omega$ denotes a sample space; $\mathcal{F}$ denotes a $\sigma$ algebra; $\mathcal{P}$ denotes a probability measure. Let valuation date be $t$. Consider a fixedfor-floating swap. Two counterparties are denoted as A and B. Counterparty A pays a fixed rate, while counterparty B pays a floating-rate. 
Assume the IRS has the first reset date $T_{0}$ and payment dates $T_{1}, \ldots, T_{n}$. There are total $\mathrm{n}$ future cash flows $X_{i}$. From the perspective of counterparty $\mathrm{A}$, The $X_{i}$ is given by

$$
X_{i}=\left(F_{i}\left(T_{i-1}\right)-K\right) \tau_{i}
$$

We are considering that fixed rate payments and floating-rate payments occur at the same payment dates and with the same day-count conventions, and ignoring the swap funding spread. Though the generalization to different payment dates, daycount conventions and swap funding spreads is straight-forward, we prefer to present a simplified version to ease the notation.

\section{Risk-Free IRS Valuation}

The discounted payoff of the IRS is

$$
\operatorname{payoff}^{\text {Free }}(t)=\sum_{i=1}^{n} D\left(t, T_{i}\right)\left(F_{i}\left(T_{i-1}\right)-K\right) \tau_{i}
$$

where $D\left(t, T_{i}\right)$ is the discount factor. In general, bond price is deterministic but discount factor is stochastic. If interest rates are deterministic, the bond price $P\left(t, T_{i}\right)$ and the discount factor $D\left(t, T_{i}\right)$ are equivalent. However, if interest rates are stochastic, they are different. In fact, the bond price can be viewed as the expectation of the discount factor.

The pricing of the IRS can be obtained by considering the risk-neutral expectation $\mathrm{E}$ of its discounted payoff:

$$
\begin{aligned}
p v^{\text {Free }}(t) & =E_{t}\left\{\sum_{i=1}^{n} D\left(t, T_{i}\right)\left(F_{i}\left(T_{i-1}\right)-K\right) \tau_{i}\right\} \\
& =\sum_{i=1}^{n} P\left(t, T_{i}\right)\left[E_{t}^{i}\left(F_{i}\left(T_{i-1}\right)-K\right) \tau_{i}\right]=\sum_{i=1}^{n} P\left(t, T_{i-1}\right)\left(F_{i}(t)-K\right) \tau_{i}
\end{aligned}
$$


Where $E_{t}:=E\left\{. \mid \mathcal{F}_{t}\right\}$ is the expectation conditional on the $\mathcal{F}_{t} ; E_{t}^{i}$ is the expectation under forward measure $Q^{i}$ conditional on the $\mathcal{F}_{t}$.

The swap rate is the fixed rate that makes the market value of a given swap at initiation zero. The risk free swap rate is given by

$$
S_{0, n}^{\text {Free }}(t)=\frac{\sum_{i=1}^{n} F_{i}(t) \tau_{i} P\left(t, T_{i}\right)}{\sum_{i=1}^{n} \tau_{i} P\left(t, T_{i}\right)}
$$

\section{Asymmetric Defaultable IRS Valuation}

There are two approaches to price defaultable financial instruments: Structural Approach and Reduced-Form Approach. The structural approach regards default as an endogenous event by focusing on the capital structure of the firm. Rendleman (1992) applies the structural model based on knowledge of the assetliability structure of the swap counterparties to the swaps market. The development of a structural model seems impractical given the data on generic market swap rates.

The reduced-form approach proposed by Duffie and Singleton (1999), and Jarrow and Turnbell (1994) did not explain the event of default endogenously, but characterized it exogenously by a jump process.

For the case of IRS's, modeling the default time as an inaccessible stopping time, such as a Poisson arrival, seems reasonable because default events, when they do occurs, are rarely fully anticipated even a short time before the default.

The stopping (default) time of party $j(j=A, B)$ is modeled as a Poisson arrival with probability density function:

$$
f_{j}(t)=h_{j}(t) \exp \left(-h_{j}(t) t\right)
$$


where $h_{j}(t)$ is the hazard rate or the arrival intensity of a Poisson process whose first jump occurs at default. The stopping time for the IRS is defined as $\tau=\tau_{A} \wedge \tau_{B}$. It is well-known that the survival probability from $t$ to $T$ in this framework is given by

$$
P S_{j}(t, T)=E\left[\exp \left(-\int_{t}^{T} h_{j}(u) d u\right)\right]
$$

We follow the common market practice and use a deterministic intensity model for hazard rate. The intensity function can be stripped by market prices of credit derivatives actively traded in the market, such as, Credit Default Swap (CDS).

In some previous studies, such as Duffie and Huang (1996), the bond spreads are used to determine credit quality. Both bond spreads and CDS spreads are closely related to each other. Conceptually a CDS spread is different from a bond spread and that they can differ in magnitude for technical reason. There is some empirical evidence that the CDS market typically leads the bond market, in particular during crisis situation. Liquidity in the bond market is typically drying up during a financial crisis. Demand for insurance against default risk, on the other hand, increases if the issuer is experiencing financial stress. Consequently, prices and spreads derived from the CDS market tend to be more reliable during crises. Therefore, we use CDS spreads to calibrate hazard rates. We will generally refer to both as credit spreads unless otherwise noted.

A critical ingredient of the pricing of a defaultable IRS is the rules for settlement in default. There are two rules in the swap market. The "one-way payment (fault)" rule was specified by the early International Swap Dealers Association (ISDA) master agreement. The non-defaulting party is not obligated to compensate the defaulting party if the remaining market value of the IRS is positive for the defaulting party. The "two-way payment (no fault)" rule is based on the current ISDA documentation. In the event of default, if the contract has positive 
value to the non-defaulting party, the defaulting party pays a fraction of the predefault market value of the IRS to the non-defaulting party. If the contract has positive value to the defaulting party, the non-defaulting party will pay the full predefault market value of the IRS to the defaulting party.

Consider any swaplet i. According to Duffie and Huang (1996), we can get the discounted defaultable payoff as

$$
\begin{aligned}
\operatorname{payoff}_{i}^{D}(t) & =D\left(t, T_{i}\right)\left[X_{i} \exp \left(-\int_{t}^{T_{i}} R(u) d u\right)\right] \\
& =D\left(t, T_{i}\right)\left[X_{i} \exp \left(-\int_{t}^{T_{i}}\left(1_{X_{i} \geq 0} s_{B}(u)+1_{X_{i}<0} s_{A}(u)\right) d u\right)\right]
\end{aligned}
$$

where

$$
\begin{aligned}
& R(u)=1_{X_{i} \geq 0} s_{B}(u)+1_{X_{i}<0} s_{A}(u) \\
& s_{B}(u)=\left(1-\varphi_{B}(u)\right) h_{B}(u)+\left(1-\bar{\varphi}_{B}(u)\right) h_{A}(u) \\
& s_{A}(u)=\left(1-\varphi_{A}(u)\right) h_{A}(u)+\left(1-\bar{\varphi}_{A}(u)\right) h_{B}(u)
\end{aligned}
$$

where $1_{Y}$ is an indicator function that is equal to one if $Y$ is true and zero otherwise; $\varphi_{j}$ represents the fraction of the cash flow $X_{i}$ paid by the defaulting counterparty $\mathrm{j}$ when the cash flow is negative for $\mathrm{j}$. The recovery rate $\varphi_{j}$ is normally considered as deterministic, although it can be time-varying. $\bar{\varphi}_{j}$ represents the fraction of the cash flow $X_{i}$ paid by non-defaulting counterparty $j$ when the cash flow is negative for $j$. $\bar{\varphi}_{j}=0$ represents the one-way settlement rule, while $\bar{\varphi}_{j}=1$ represents two-way settlement rule. $h_{j}$ is the hazard rate of counterparty $j$.

The default-adjusted spreads $s_{B}$ and $s_{A}$ in (12) have general forms that apply in several particular situations. Under the one-way settlement rule, we have

$$
s_{B}(u)=\left(1-\varphi_{B}(u)\right) h_{B}(u)+h_{A}(u)
$$




$$
s_{A}(u)=\left(1-\varphi_{A}(u)\right) h_{A}(u)+h_{B}(u)
$$

Under the two-way settlement rule, we have

$$
\begin{aligned}
& s_{B}(u)=\left(1-\varphi_{B}(u)\right) h_{B}(u) \\
& s_{A}(u)=\left(1-\varphi_{A}(u)\right) h_{A}(u)
\end{aligned}
$$

Equation (12) can be rewritten as

$$
\begin{aligned}
\operatorname{payoff}_{i}^{D}(t) & =D\left(t, T_{i}\right)\left[X_{i} 1_{X_{i} \geq 0} \exp \left(-\int_{t}^{T_{i}} s_{B}(u) d u\right)+X_{i} 1_{X_{i}<0} \exp \left(-\int_{t}^{T_{i}} s_{A}(u) d u\right)\right] \\
& =D\left(t, T_{i}\right)\left[C_{B}\left(t, T_{i}\right) X_{i} 1_{X_{i} \geq 0}+C_{A}\left(t, T_{i}\right) X_{i} 1_{X_{i}<0}\right]
\end{aligned}
$$

where $C_{j}\left(t, T_{i}\right)=\exp \left(-\int_{t}^{T_{i}} s_{j}(u) d u\right)$ is a deterministic function under a deterministic default intensity model and a deterministic recovery assumption.

An IRS is a linear product. The total discounted defaultable payoff of the IRS is just the sum of the discounted defaultable payoffs of the future swaplets, that is,

$$
\operatorname{payoff}^{D}(t)=\sum_{i=1}^{n} D\left(t, T_{i}\right)\left[C_{B}\left(t, T_{i}\right) X_{i} 1_{X_{i} \geq 0}+C_{A}\left(t, T_{i}\right) X_{i} 1_{X_{i}<0}\right]
$$

The price of the defaultable IRS can be obtained by considering the riskneutral expectation $\mathrm{E}$ of its discounted defaultable payoff:

$$
\begin{aligned}
p v^{D}(t) & =E_{t}\left\{\sum_{i=1}^{n} D\left(t, T_{i}\right)\left[C_{B}\left(t, T_{i}\right) X_{i} 1_{X_{i} \geq 0}+C_{A}\left(t, T_{i}\right) X_{i} 1_{X_{i}<0}\right]\right\} \\
& =\sum_{i=1}^{n} P\left(t, T_{i}\right) E_{t}^{i}\left[C_{B}\left(t, T_{i}\right) X_{i} 1_{X_{i} \geq 0}+C_{A}\left(t, T_{i}\right) X_{i} 1_{X_{i}<0}\right] \\
& =\sum_{i=1}^{n} P\left(t, T_{i}\right)\left[C_{B}\left(t, T_{i}\right) E_{t}^{i}\left(X_{i} 1_{X_{i} \geq 0}\right)+C_{A}\left(t, T_{i}\right) E_{t}^{i}\left(X_{i} 1_{X_{i}<0}\right)\right]
\end{aligned}
$$

The key to value an asymmetric defaultable IRS is to calculate the expectations: $E_{t}^{i}\left(X_{i} 1_{X_{i} \geq 0}\right)$ and $E_{t}^{i}\left(X_{i} 1_{X_{i}<0}\right)$.

According to (3), we can calculate 


$$
\begin{aligned}
E_{t}^{i}\left(X_{i} 1_{X_{i} \geq 0}\right) & =E_{t}^{i}\left[\left(F_{i}\left(T_{i-1}\right)-K\right) \tau_{i} 1_{F_{i}\left(T_{i-1}\right)-K \geq 0}\right\rfloor \\
& =\tau_{i} \int_{-d_{i 2}}^{\infty}\left[F_{i}(t) \exp \left(-\frac{\sigma_{i}^{2}\left(T_{i-1}-t\right)}{2}+\sigma_{i} \sqrt{T_{i-1}-t} x\right)-K\right] \frac{1}{\sqrt{2 \pi}} \exp \left(-\frac{x^{2}}{2}\right) d x \\
& =\tau_{i}\left(F_{i}(t) \Phi\left(d_{i 1}\right)-K \Phi\left(d_{i 2}\right)\right)
\end{aligned}
$$

where $x$ is a standard normal variable; $\Phi$ is the standard normal cumulative distribution function; $d_{i 1, i 2}=\frac{\ln \left(F_{i}(t) / K\right) \pm \sigma_{i}^{2}\left(T_{i}-t\right) / 2}{\sigma_{i} \sqrt{T_{i}-t}}$. Equation (16) is a standard Black formula on a call option.

Similarly, we have

$$
E_{t}^{i}\left(X_{i} 1_{X_{i}<0}\right)=E_{t}^{i}\left[\left(F_{i}\left(T_{i-1}\right)-K\right) \tau_{i} 1_{F_{i}\left(T_{i-1}\right)-K<0}\right]=-\tau_{i}\left[K \Phi\left(-d_{i 2}\right)-F_{i}(t) \Phi\left(-d_{i 1}\right)\right]
$$

This is a standard Black formula on a put option.

Therefore, the value of a defaultable swaplet is a risk-adjusted call option minus a risk-adjusted put option. In other words, a defaultable swaplet can be replicated by buying a risk-adjusted call option and selling a risk-adjusted put option, that is:

$$
\begin{aligned}
p v_{i}^{D}(t) & =P\left(t, T_{i}\right) C_{B}\left(t, T_{i}\right) E_{t}^{T_{n}}\left\lfloor 1_{X_{T_{i}} \geq 0} X_{T_{i}}\right\rfloor+P\left(t, T_{i}\right) C_{A}\left(t, T_{i}\right) E_{t}^{T_{n}}\left\lfloor 1_{X_{T_{i}}<0} X_{T_{i}}\right\rfloor \\
& =P\left(t, T_{i}\right) \tau_{i}\left\{C_{B}\left(t, T_{i}\right)\left(F_{i}(t) \Phi\left(d_{i 1}\right)-K \Phi\left(d_{i 2}\right)\right)-C_{A}\left(t, T_{i}\right)\left(K \Phi\left(-d_{i 2}\right)-F_{i}(t) \Phi\left(-d_{i 1}\right)\right)\right\}
\end{aligned}
$$

The price of the defaultable IRS is

$$
\begin{aligned}
p v^{D}(t)= & \sum_{i=1}^{n} P\left(t, T_{i}\right)\left[C_{B}\left(t, T_{i}\right) E_{t}^{i}\left(X_{i} 1_{X_{i} \geq 0}\right)+C_{A}\left(t, T_{i}\right) E_{t}^{i}\left(X_{i} 1_{X_{i}<0}\right)\right] \\
= & \sum_{i=1}^{n} P\left(t, T_{i}\right) \tau_{i}\left\{C_{B}\left(t, T_{i}\right)\left(F_{i}(t) \Phi\left(d_{i 1}\right)-K \Phi\left(d_{i 2}\right)\right)\right. \\
& \left.\quad-C_{A}\left(t, T_{i}\right)\left(K \Phi\left(-d_{i 2}\right)-F_{i}(t) \Phi\left(-d_{i 1}\right)\right)\right\}
\end{aligned}
$$

If both parties have the same credit quality (symmetric credit risk) and follow two-way settlement rule, i.e., 


$$
C\left(t, T_{i}\right)=C_{A}\left(t, T_{i}\right)=C_{B}\left(t, T_{i}\right)=\exp \left(-\int_{t}^{T_{i}} s(u) d u\right)=\exp \left(-\int_{t}^{T_{i}} h(u)(1-\varphi(u)) d u\right)
$$

equation (19) can be expressed as

$$
\begin{aligned}
p v^{D}(t)= & \sum_{i=1}^{n} P\left(t, T_{i}\right) \tau_{i} C\left(t, T_{i}\right)\left\{\left(F_{i}(t) \Phi\left(d_{i 1}\right)-K \Phi\left(d_{i 2}\right)\right)\right. \\
& \left.-\left(K \Phi\left(-d_{i 2}\right)-F_{i}(t) \Phi\left(-d_{i 1}\right)\right)\right\} \\
= & \sum_{i=1}^{n} P\left(t, T_{i}\right) \tau_{i} C\left(t, T_{i}\right)\left(F_{i}(t)-K\right)
\end{aligned}
$$

where $\Phi(x)+\Phi(-x)=1$.

This is exactly the formula of Duffie and Singleton (1997). The defaultable swap rate $(\mathrm{K})$ under asymmetric credit risk can only be solved numerically, because $\mathrm{K}$ is also contained in $d_{i 1}$ and $d_{i 2}$. However, the analytic solution exists for the defaultable swap rate under symmetric credit risk. The symmetric defaultable swap rate that makes the market value of the IRS at initiation zero is

$$
S_{0, n}^{D}(t)=\frac{\sum_{i=1}^{n} P\left(t, T_{i}\right) \tau_{i} F_{i}(t) C\left(t, T_{i}\right)}{\sum_{i=1}^{n} P\left(t, T_{i}\right) \tau_{i} C\left(t, T_{i}\right)}
$$

\section{Bilateral CVA}

CVA offers an opportunity for banks to move beyond the traditional control mindset of credit risk limits by dynamically pricing counterparty credit risk directly into new trades. A trend that has become increasingly relevant and popular has been to consider the bilateral nature of counterparty credit risk. Most institutions view bilateral considerations as important in order to agree on new transactions. The bilateral CVA of an IRS, by definition, is the difference between the risk-free IRS value and the bilateral defaultable IRS value, given by

$$
C V A(t)=p v^{\text {Free }}(t)-p v^{D}(t)
$$


Unlike the unilateral CVA that is always positive, the bilateral CVA can be positive or negative. Since the swaps market is a zero-sum game, for every winner there is an equal and opposite loser.

\section{Impact of Credit Risk}

We use a new 10-year IRS as an example. At the time the contract is entered into, there is no advantage to either party. Thus, the risk free value of the IRS is zero, i.e., $p v^{\text {Free }}(t)=0$. The risk free swap rate calculated according to (10) is $2.59 \%$. The 10 -year treasury yield is $2.58 \%$. The risk-free swap spread is 1 basis point. Swap spread is defined as the spread paid by the fixed-rate payer of an IRS over the rate of the on-the-run treasury with the same maturity as the IRS. The swap spread is the additional amount an investor would earn on an IRS as compared to a risk-free fixed rate investment. We report the empirical results in several cases.

\section{LIBOR Party Paying Floating-Rate}

LIBOR reflects an average of the borrowing costs for large banks with AA credit rating. A hypothetical LIBOR quality entity can issue floating bonds at LIBOR flat, i.e., with par coupon being the same as LIBOR. But an entity with lower credit quality than LIBOR can only issue bonds at LIBOR plus positive spreads so as to compensate the bondholders for the credit risk that they undertake. These credit spreads are the credit funding cost for this entity. The swap funding spread (floatingrate spread) is different from the credit spread but is of the same origin. We assume that a LIBOR floating payer enter a par swap with zero swap funding spread.

Let the floating-rate payer have the same credit quality as LIBOR and the second party have a parallel shifted spread against the LIBOR party. Assume that the second party has a constant recovery rate $60 \%$. The hazard rates are bootstrapped 
from CDS spreads. The defaultable IRS values, CVA's, swap rates and swap spreads, from the perspective of counterparty A, are calculated according to the description of section 3 and shown in Table 1.

\section{Table 1}

Credit quality impact (the floating-rate payer is a LIBOR party; the swap funding spread is 0; swap spread change = defaultable swap spread - default-free swap spread)

\begin{tabular}{|c|c|c|c|c|c|}
\hline \multicolumn{2}{|c|}{ Rating } & \multirow{2}{*}{$\begin{array}{l}\text { Defaultable } \\
\text { IRS value }\end{array}$} & \multirow{2}{*}{ CVA } & \multirow{2}{*}{$\begin{array}{c}\text { Defaultable } \\
\text { swap rate }\end{array}$} & \multirow{2}{*}{$\begin{array}{c}\text { Swap spreac } \\
\text { change }\end{array}$} \\
\hline party $A$ & party B & & & & \\
\hline$A A+100 b p$ & AA & 147.4069 & -147.4069 & $2.6061 \%$ & $1.6 \mathrm{bp}$ \\
\hline$A A+200 b p$ & AA & 286.5230 & -286.5230 & $2.6222 \%$ & $3.2 b p$ \\
\hline$A A+300 b p$ & AA & 420.9761 & -420.9761 & $2.6383 \%$ & $4.8 \mathrm{bp}$ \\
\hline
\end{tabular}

From table 1, we find that a credit spread of about 100 basis points translates into a swap spread of about 1.6 basis points. The credit impact on swap rates is approximately linear within the range of normally encountered credit quality. This confirms the findings of Duffie and Huang (1996).

The magnitude of the difference between the credit spread and swap spread can by explained by the exposure and the credit risk. In the case of a bond, all coupons and the principal are at risk. In the case of an IRS, only net cashflows are at risk. The impact of net cashflows is much smaller than that of all cashflows plus principal.

\section{Both Parties Having Spreads against the LIBOR}

Now we are considering the cases that both parties have credit spreads against the LIBRO. If the party who pays the floating-rate has a credit quality different from the LIBOR, a swap funding spread is also needed to be introduced. 
This funding spread actually reflects the different funding cost of different issuers and also has an impact on swap rate. To simplify the analysis, we fix the swap funding spread and assume the floating-rate payer has 100 basis points against the LIBOR. The results are shown in Table 2 and table 3. We show that the swap funding spread has a significant impact on swap spread as well. If we fix the swap funding spread, the swap spreads increase as the credit spreads of the two parties increase. But the impact is not linear any more.

\section{Table 2}

Credit quality impact (both parties are not a LIBOR party; the swap funding spread is $0.1 \%$; swap spread change = defaultable swap spread - default-free swap spread)

\begin{tabular}{|c|c|c|c|c|c|}
\hline \multicolumn{2}{|c|}{ Rating } & \multirow{2}{*}{$\begin{array}{c}\text { Defaultable } \\
\text { IRS value }\end{array}$} & \multirow{2}{*}{ CVA } & \multirow{2}{*}{$\begin{array}{c}\text { Defaultable } \\
\text { swap rate }\end{array}$} & \multirow{2}{*}{$\begin{array}{c}\text { Swap spread } \\
\text { change }\end{array}$} \\
\hline party $A$ & party B & & & & \\
\hline$A A+100 b p$ & $A A+100 b p$ & 220.1629 & -220.1629 & $2.6148 \%$ & $2.4 b p$ \\
\hline$A A+200 b p$ & $A A+100 b p$ & 286.5230 & -286.5230 & $2.6309 \%$ & $4.1 \mathrm{bp}$ \\
\hline$A A+300 b p$ & $A A+100 b p$ & 420.9761 & -420.9761 & $2.6469 \%$ & $5.7 \mathrm{bp}$ \\
\hline
\end{tabular}

Table 3

Credit quality impact (both parties are not a LIBOR party; the swap funding spread is $0.12 \%$; swap spread change = defaultable swap spread - default-free swap spread)

\begin{tabular}{|c|c|c|c|c|c|}
\hline \multicolumn{2}{|c|}{ Rating } & \multirow{2}{*}{$\begin{array}{l}\text { Defaultable } \\
\text { IRS value }\end{array}$} & \multirow{2}{*}{ CVA } & \multirow{2}{*}{$\begin{array}{c}\text { Defaultable } \\
\text { swap rate }\end{array}$} & \multirow{2}{*}{$\begin{array}{c}\text { Swap spread } \\
\text { change }\end{array}$} \\
\hline party A & party B & & & & \\
\hline$A A+100 b p$ & $A A+100 b p$ & 394.4319 & -394.4319 & $2.6347 \%$ & $4.5 b p$ \\
\hline$A A+200 b p$ & $A A+100 b p$ & 527.6796 & -527.6796 & $2.6510 \%$ & $6.1 \mathrm{bp}$ \\
\hline$A A+300 b p$ & $A A+100 b p$ & 656.4207 & -656.4207 & $2.6670 \%$ & $7.8 \mathrm{bp}$ \\
\hline
\end{tabular}

\section{Conclusion}


In this paper we present an analytical model for pricing defaultable IRS's with asymmetric credit qualities. The model is based on the market models of interest rate dynamics and the reduced-form model of default time.

The object modeled under the market models is market-observable. It is also consistent with the market standard approach for pricing caps/floors using Black's formula. The market models have now become some of the most popular models for pricing such derivatives. They are generally considered to have more desirable theoretical calibration properties than short rate or instantaneous forward rate models.

Unlike structural models, reduced-form models do not condition default explicitly on the value of the firm, and parameters related to the firm's value need not be estimated to implement the model. For pricing and hedging, reduced-form models are the preferred methodology.

Our closed-form solution shows that the value of a bilateral defaultable IRS is the sum of the values of individual bilateral defaultable swaplets. Each bilateral defaultable swaplet can be replicated by buying a risk-adjusted call option and selling a risk-adjusted put option. The risk-adjusting factors depend on hazard rates, recovery rates and settlement rules.

In the case where the floating-rate payer is a LIBOR party, we confirm findings in Duffie and Huang (1996) that the swap spreads are relatively less sensitive to credit quality comparing to the bond spreads or the CDS spreads. The credit impact on swap rates is approximately linear. In the case where both parties have spreads against the LIBOR that was not studied closely before, we find that the credit impact on swap rates is not linear any more. The swap funding spreads have a significantly impact on swap spreads as well.

\section{Reference}


ArVanities, A., and Gregory, J., 2001, Credit: the complete guide to pricing, hedging and risk management, Risk Books.

Duffie, D. and Huang, M., 1996, Swap rates and credit quality, Journal of Finance, $51,921-949$.

Duffie, D. and Singleton, K.J., 1997, An econometric model of the term structure of interest rate swap yields, Journal of Finance, 52, 1287-1321

Huge, B. and Lando, D., 1999, Swap pricing with two-sided default risk in a ratingbased model, European Finance Review, 3, 239-268.

Hubner, G., 2001, The analytic pricing of asymmetric defaultable swaps, Journal of Banking \& Finance, 25, 295-316

Jarrow, R. and Turnbull, S., 1995, Pricing options on financial securities subject to default risk, Journal of Finance, 50, 53-86.

Li, H., 1998, Pricing of swaps with default risk, Review of Derivatives Research, 2, 231-250.

Longstaff, F.A. and Schwartz, E.S., 1993, Valuing risky debt: a new approach, working paper, The Anderson Graduate School of Management, UCLA.

Rendleman, R.J., 1992, How risks are shared in interest rate swaps, Journal of Financial Services Research, 7, 5-34. 
Sundarean, S., 1991, Valuation of swaps, in Recent Developments in International Banking and Finance, S. Khoury, ed. Amsterdam: North Holland.

Tang, Y. and Li, B., 2007, Quantitative analysis, derivatives modeling, and trading strategies, World Scientific Publishing. 